Article

\title{
Serial Disulfide Polymers as Cathode Materials in Lithium-Sulfur Battery: Materials Optimization and Electrochemical Characterization
}

\author{
Jing Wang and Shichao Zhang * \\ School of Material Science and Engineering, Bei Hang University, Beijing 100083, China; by1201141@buaa.edu.cn \\ * Correspondence: csc@buaa.edu.cn
}

Received: 17 March 2020; Accepted: 2 April 2020; Published: 7 April 2020

check for updates

\begin{abstract}
Herein, a series of novel disulfide polymers were synthesized by using the raw materials of diallyl-o-phthalate, tung oil, peanut oil, and styrene. Four kinds of products: Poly (sulfur-diallyl-o-phthalate) copolymer, poly (sulfur-tung oil) copolymer, poly (sulfur-peanut oil) copolymer, and poly (sulfur-styrene-peanut oil) terpolymer were characterized, and their solubility was studied and compared. Among the four kinds of disulfide polymers, poly (sulfur-styrene-peanut oil) terpolymer had the best solubility in an organic solvent, and it was chosen to be the active cathode material in Li-S battery. Subsequently, two different conductive additives-conductive carbon black and graphene were separately blended with this terpolymer to prepare two battery systems. The electrochemical performances of the two batteries were compared and analyzed. The result showed that the initial specific capacity of poly (sulfur-styrene-peanut oil) terpolymer (blended with conductive carbon black) battery was $935.88 \mathrm{mAh} / \mathrm{g}$, with the capacity retention rate about $43.5 \%$. Comparingly, the initial specific capacity of poly (sulfur-styrene-peanut oil) terpolymer (blended with graphene) battery was $1008.35 \mathrm{mAh} / \mathrm{g}$, with the capacity retention rate around $60.59 \%$. Therefore, the battery system of poly (sulfur-styrene-peanut oil) terpolymer with graphene showed a more stable cycle performance and better rate performance. This optimized system had a simple and environmental-friendly synthesis procedure, which showed a great application value in constructing cathode materials for the Li-S battery.
\end{abstract}

Keywords: lithium-sulfur batteries; disulfide polymer; cathode materials

\section{Introduction}

Compared with the present cathode materials, sulfur has a higher specific capacity $(1675 \mathrm{mAh} / \mathrm{g})$, and the theoretical energy density of lithium-sulfur (Li-S) battery is as high as $2600 \mathrm{wh} / \mathrm{kg}$, which is 3-5 times larger than other traditional lithium-ion batteries [1]. However, the Li-S battery also has several disadvantages, for example, the conductivity of sulfur at room temperature is low $\left(5.0 \times 10^{-30} \mathrm{~S} / \mathrm{cm}\right)$ and the final products $\mathrm{Li}_{2} \mathrm{~S}_{2}$ and $\mathrm{Li}_{2} \mathrm{~S}$ are nonconductive, which limits the rate performance of Li-S battery. Moreover, the intermediates of Li-S battery will dissolve in the organic electrolyte and diffuse across the membrane to the negative electrode, which results in the irreversible loss of the active substance and decay of battery cycle life, causing the "shuttle effect". In addition, parts of lithium sulfide are removed from the conductive framework and cannot be converted into $\mathrm{S}_{8}$ or other high-order polysulfides in the charge-discharge process, which greatly affects the specific capacity [2]. Therefore, it has become important to construct a suitable cathode material system to solve these problems. 
The polymer cathode material with high sulfur content has a simple preparation process, low reaction temperature, and it has various molecular structures which are beneficial for material design. Yuzhong M. et al. [3] prepared the sulfur-containing composite based on linear polymer, in order to gather, fix, and connect the element sulfur with each other through a dynamic covalent bond [4]. During the charge-discharge process, the energy storage and release can be realized via the break and reconnection of sulfur-sulfur bond, which can reduce the generation of intermediates, and effectively protect the active substances from being dissolved in the electrolyte, and then improve the battery efficiency $[5,6]$.

However, above $159^{\circ} \mathrm{C}$, the octasulfur ring will be opened, and the end groups are linear polysulfide chains with sulfur radical, which will be polymerized into the homopolysulfide with higher molecular weight. This kind of homopolysulfide has poor solubility and fusibility. To solve this problem, the inverse vulcanization [7-10] method was invented to prepare polymers with high sulfur content. In this process, molten sulfur was directly copolymerized with vinyl monomers, which not only increased the branching of sulfur chains, but also produced polysulfide rings. These changes effectively inhibited the depolymerization of homopolysulfides and enhanced the processability of the products [11,12].

Sun et al. [13] prepared a sulfur-based polymer via inverse vulcanization by using 1,3-diacetyrylbenzene (DEB) and sulfur. It was found that diyne or polydiyne in the polymer had crosslinked with sulfur, forming a semi-interpenetrating network structure. This special cage-like structure effectively inhibited the "shuttle effect" and enhanced battery performance. Arslan et al. [14] prepared a copolymer of sulfur-bismaleimide (BMI) via inverse vulcanization and used this copolymer as cathode material. The specific capacity of the battery after 50 cycles was about $400 \mathrm{mAh} / \mathrm{g}$. Inaki et al. [15] synthesized copolymers of sulfur-divinylbenzene (DVB) via inverse vulcanization and utilized it as cathode material. The specific capacity of this product can match up with that of carbon/sulfur cathode material. Swapnil et al. [16] prepared the phenol benzoxazine monomer-sulfur random copolymer at $185^{\circ} \mathrm{C}$ and found that the curing temperature decreased from 242 to $185^{\circ} \mathrm{C}$. When this copolymer was used as cathode material, the specific capacity of the battery kept at $1006 \mathrm{mAh} / \mathrm{g}$ after 75 cycles.

Though plenty of sulfur-based polymers have been prepared as cathode materials in Li-S battery, most reactants were aromatic hydrocarbons or compounds with relatively low polarity, which greatly limited the preparation and application of the Li-S battery.

Herein, to develop more reactants and to simplify the preparation process, a series of disulfide polymers was synthesized via the method of inverse vulcanization and dynamic covalent polymerization (DCP) [17-19]. Diallyl-o-phthalate, tung oil, peanut oil, and styrene were used as reactants and four kinds of sulfur-based polymers were synthesized. Among the products, the poly (sulfur-styrene-peanut oil) terpolymer showed the best solubility and electrode processability: It was viscous, and it can be completely soluble in the tetrahydrofuran solution at room temperature. Therefore, it was utilized both as an active substance of the cathode material and as a binder in Li-S batteries. In addition, this novel terpolymer was separately mixed with different conductive additives: Conductive carbon black and graphene. The properties of these two battery systems were compared and the result showed that the battery system of poly (sulfur-styrene-peanut oil) terpolymer with graphene had a more stable cycle performance and better rate performance than the battery system of poly (sulfur-styrene-peanut oil) terpolymer with conductive carbon black. The optimized battery system proved that the monomer without benzene ring can also react with molten sulfur and can be successfully utilized as the cathode material in Li-S battery. 


\section{Experiment}

\subsection{Material Preparation}

\subsubsection{Synthesis of Poly (sulfur-diallyl-o-phthalate) (Poly(S-DAP)) Copolymer}

The poly (sulfur-diallyl-o-phthalate) copolymer was synthetized via inverse vulcanization. Firstly, diallyl-o-phthalate (DAP, 98\%, Shanghai meiruier Chemical Technology Co., Ltd. (Shanghai China)) was injected into the molten sulfur $\left(99.5+\%\right.$, Acros Organics) at $120{ }^{\circ} \mathrm{C}$ at a mass ratio of $3: 7$ (sulfur: $70 \mathrm{wt} \%$ ). The mixture was heated at $130^{\circ} \mathrm{C}$ for $2.5 \mathrm{~h}$. The yellow solid product, as shown in Figure 1 , was washed with acetone (AR, Beijing chemical plant) and dried in the vacuum drier (DZF2001, Shanghai Yiheng Instrument Co., Ltd. (Shanghai China)).
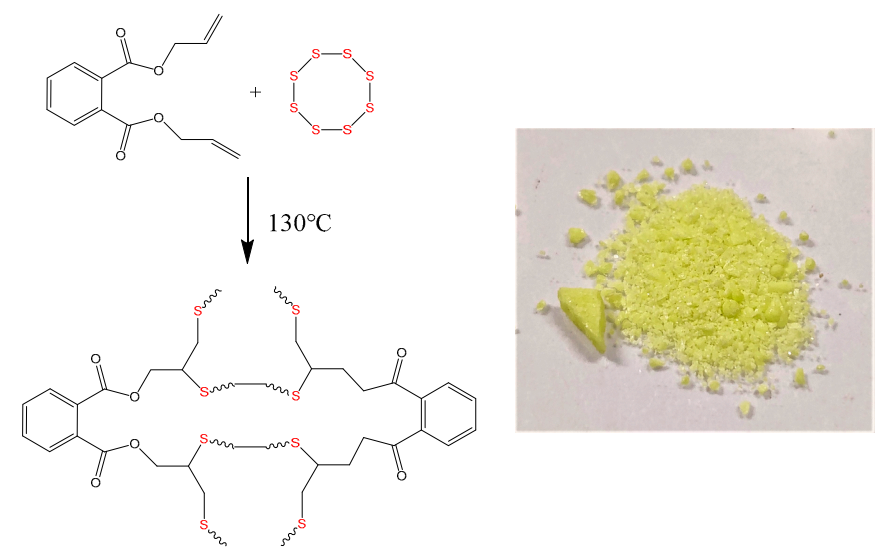

Figure 1. The reaction formula of poly (sulfur-diallyl-o-phthalate) (poly(S-DAP)) copolymer and the product photograph.

\subsubsection{Synthesis of Poly (sulfur-tung oil) (Poly(S-T)) Copolymer}

The poly (sulfur-tung oil) copolymer was synthetized via inverse vulcanization. Firstly, tung oil (Xisi chemical raw material store) was injected into the molten sulfur at $120^{\circ} \mathrm{C}$ at a mass ratio of $4: 6$ (sulfur: $60 \mathrm{wt} \%$ ). The mixture was heated at $170-180^{\circ} \mathrm{C}$ for $30-40 \mathrm{~min}$. The black solid product, as shown in Figure 2, was washed with acetone and dried in the vacuum drying oven.

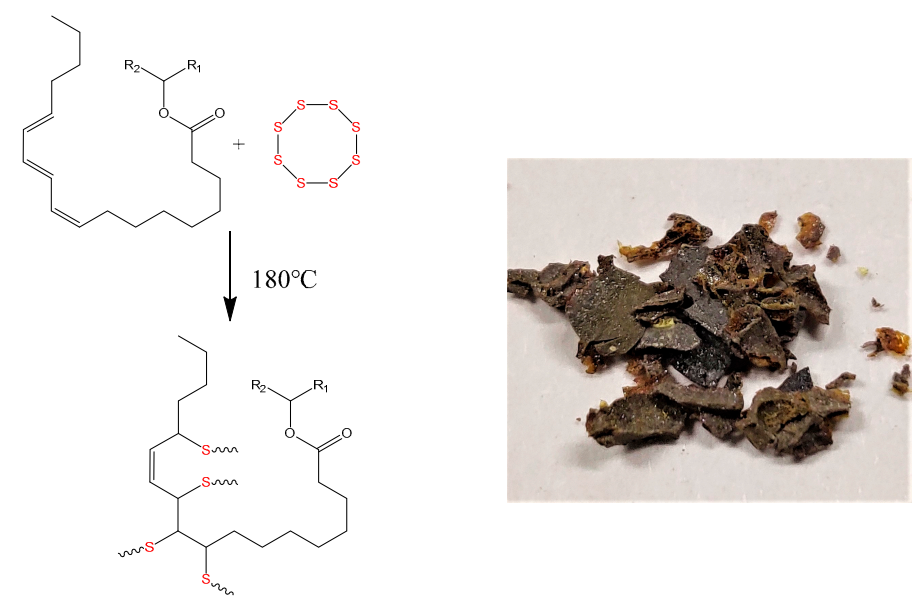

$\mathrm{R} 1, \mathrm{R} 2$ : Eleostearin, triolein, linoleate, oleate, stearate, palmitate

Figure 2. The reaction formula of poly (sulfur-tung oil) (poly(S-T)) copolymer and the product photograph. 


\subsubsection{Synthesis of Poly (sulfur-peanut oil) (Poly(S-P)) Copolymer}

The poly (sulfur-peanut oil) copolymer was synthetized via inverse vulcanization. Firstly, peanut oil (roasted, Yangjiang Yangdong Food and Spice Co., Ltd. (Guangdong, China)) was injected into the molten sulfur at $120{ }^{\circ} \mathrm{C}$ at a mass ratio of $4: 6$ (sulfur: $60 \mathrm{wt} \%$ ). The mixture was heated at $170-180^{\circ} \mathrm{C}$ for 30-40 min to get the brown solid product, as shown in Figure 3.

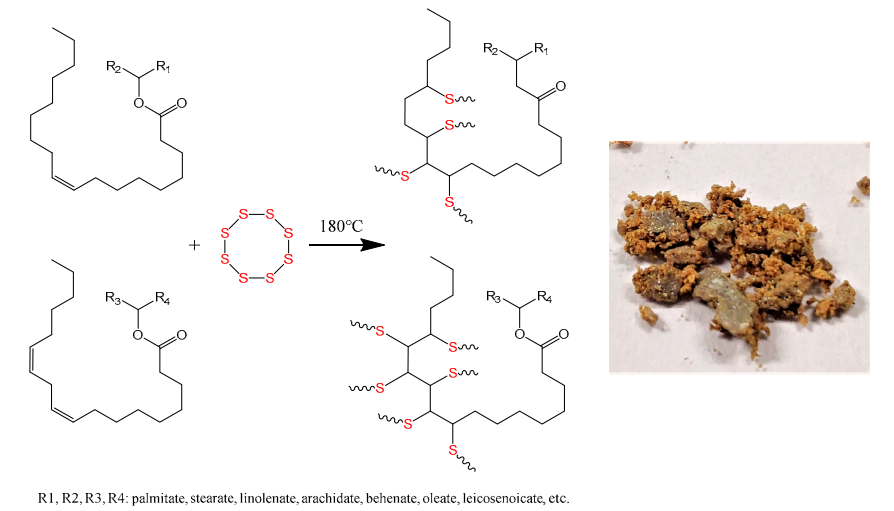

Figure 3. The reaction formula of poly (sulfur-peanut oil) (poly(S-P)) copolymer and the product photograph.

\subsubsection{Synthesis of Poly (sulfur-styrene-peanut oil) (Poly(S-Sty-P)) Terpolymer}

Firstly, styrene (98\%, Tianjin Fuchen Chemical Reagent Factory (Tianjin China)) was injected into the molten sulfur at $120^{\circ} \mathrm{C}$ at a mass ratio of 4:6 (sulfur: $60 \mathrm{wt} \%$ ). Then, the mixture was heated at 130-140 ${ }^{\circ} \mathrm{C}$ for $5-6 \mathrm{~h}$ to get a brown liquid. When the products cooled down, the intermediate product poly (sulfur-styrene) copolymer was synthetized. Then, peanut oil was injected into the molten poly (sulfur-styrene) copolymer (at 9:1 $\mathrm{wt} \%$ feed ratios), and the mixture was heated at $170-180{ }^{\circ} \mathrm{C}$ for $5 \mathrm{~h}$. After cooling down, the poly (sulfur-styrene-peanut oil) terpolymer was synthesized (calculated sulfur content: $54 \mathrm{wt} \%$ ), which was viscous at room temperature, as shown in Figure 4.

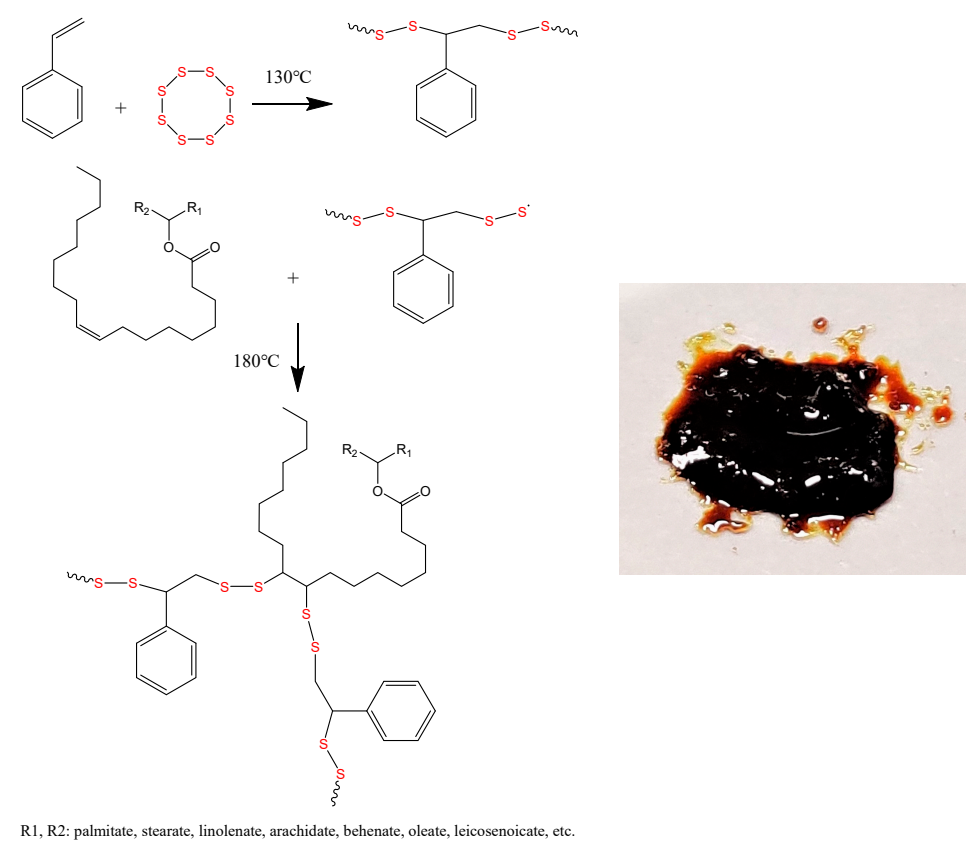

Figure 4. The reaction formula of (sulfur-styrene-peanut oil) (poly(S-Sty-P)) terpolymer and the product photograph. 


\subsection{Characterization}

Infrared spectroscopy (IR, Nicolet-60SXB) was used to characterize the four products of poly(S-DAP) copolymer, poly(S-T) copolymer, poly(S-P) copolymer, and poly(S-Sty-P) terpolymer. Ultrasonic cleaners (KQ5200DB, Kun Shan) were used to test the solubility of these disulfide polymers. The element composition was tested by nuclear magnetic resonance $\left({ }^{13} \mathrm{C}\right.$ NMR) (Bruker Avance $400 \mathrm{MHz}$ ), and the surface topography of the products was observed by the scanning electron microscopy (Zooma 200, The Netherlands).

\subsection{Electrochemical Measurement}

According to the dissolution test, poly(S-Sty-P) terpolymer had the best solubility among the disulfide polymers and it was completely soluble in the tetrahydrofuran solution (AR, Beijing Chemical Plant) at room temperature. Therefore, poly(S-Sty-P) terpolymer was chosen to prepare the cathode material. Separately, conductive carbon black and graphene were blended with the terpolymer (at a mass ratio of 3:2). Then, the mixture was stirred for about $5 \mathrm{~h}$ until the uniform slurry was obtained. Then, the slurry was coated on an aluminum foil current collector by an applicator blade and was dried in the vacuum drier at $60^{\circ} \mathrm{C}$. After that, circular electrode pieces were punched at a diameter of $1 \mathrm{~cm}$. These punched pieces were used as the positive electrode; the lithium pieces $\left(16^{*} 0.6 \mathrm{~mm}\right.$, Jiangsu Taizhou) were used as the negative electrode; Celgard 2400 microporous films were used as the separator, and $1 \mathrm{~mol} / \mathrm{L}$ LiTFSI (1,3-dioxolane/dimethoxyethane, volume ratio of 1:1) was used as the electrolyte. Finally, the button batteries were totally assembled in the glove box (Lab 2000). After $24 \mathrm{~h}$, the batteries were electrochemically tested. The charge-discharge performance and the cycle performance of the batteries were tested in the LAND CT2001A blue test system (Wuhan). The cyclic voltammetry $(\mathrm{CV})$ of the batteries was measured in the ARBIN electrochemical workstation (Suzhou Tianyi Science and Technology Co., Ltd. (Suzhou China)) at a scan rate of $0.05 \mathrm{mV} / \mathrm{s}$ and a voltage range of 1.2-3.0 V. The electrochemical impedance spectroscopy (EIS) of the cathode materials was measured in the ARBIN electrochemical workstation at the frequency range from $10^{5}$ to $10^{2} \mathrm{~Hz}$ and all cells were charged to $3 \mathrm{~V}$ before the EIS test. The specific capacity and current multiplying ratio of the batteries were calculated according to the mass of sulfur: $\mathrm{M}_{\text {terpolymer }} /\left(\mathrm{M}_{\text {terpolymer }}+\mathrm{M}_{\text {conductive agent }}\right) \times$ $54 \%$ (calculated sulfur content). Therefore, the active material amount in poly(S-Sty-P) terpolymer @ CCB cathode material was $43.67 \mathrm{wt} \%$, while the active material amount in poly(S-Sty-P) terpolymer @ GF cathode material was $45.73 \mathrm{wt} \%$.

\section{Results and Discussion}

\subsection{Characterization of Serial Disulfide Polymer}

In the infrared spectrum of the poly(S-DAP) copolymer (Figure 5a), compared with the curve of DAP, the curve of poly(S-DAP) copolymer showed an extra signal at $462 \mathrm{~cm}^{-1}$, which illustrated the existence of S-S bond. In Figure 5b, the curve of tung oil showed a signal at $3011 \mathrm{~cm}^{-1}$, which was caused by the vibration of $=\mathrm{C}-\mathrm{H}$ bond, and the signal at $993 \mathrm{~cm}^{-1}$ was attributed by three conjugates $\mathrm{C}=\mathrm{C}$. In the curve of poly(S-T) copolymer, the signals at 1581 and $799 \mathrm{~cm}^{-1}$ were caused by the vibration of C-H bond which was near the C-S bond, and there was also an indicator of S-S bond at $461 \mathrm{~cm}^{-1}$. In Figure 5c, the curves of peanut oil and poly(S-P) copolymer resembled each other, but the signal at $3009 \mathrm{~cm}^{-1}$ disappeared and a new signal at $468 \mathrm{~cm}^{-1}$ appeared, which indicated that $S$ had reacted with the $C=C$ bond. In Figure $5 d$, compared with the curves of peanut oil and styrene, the curve of poly(S-Sty-P) terpolymer changed a lot: A new signal at $468 \mathrm{~cm}^{-1}$ showed the existence of S-S bond; and the signals at 700, 776, and $3010 \mathrm{~cm}^{-1}$ indicated that the styrene was participated in the reaction. The signal at $1748 \mathrm{~cm}^{-1}$ was attributed by the vibration of $\mathrm{C}=\mathrm{O}$ bond. However, the signal at $1630 \mathrm{~cm}^{-1}$ disappeared, while the signal of the benzene ring still existed. It meant that the poly(S-Sty-P) terpolymer had been successfully synthesized. 

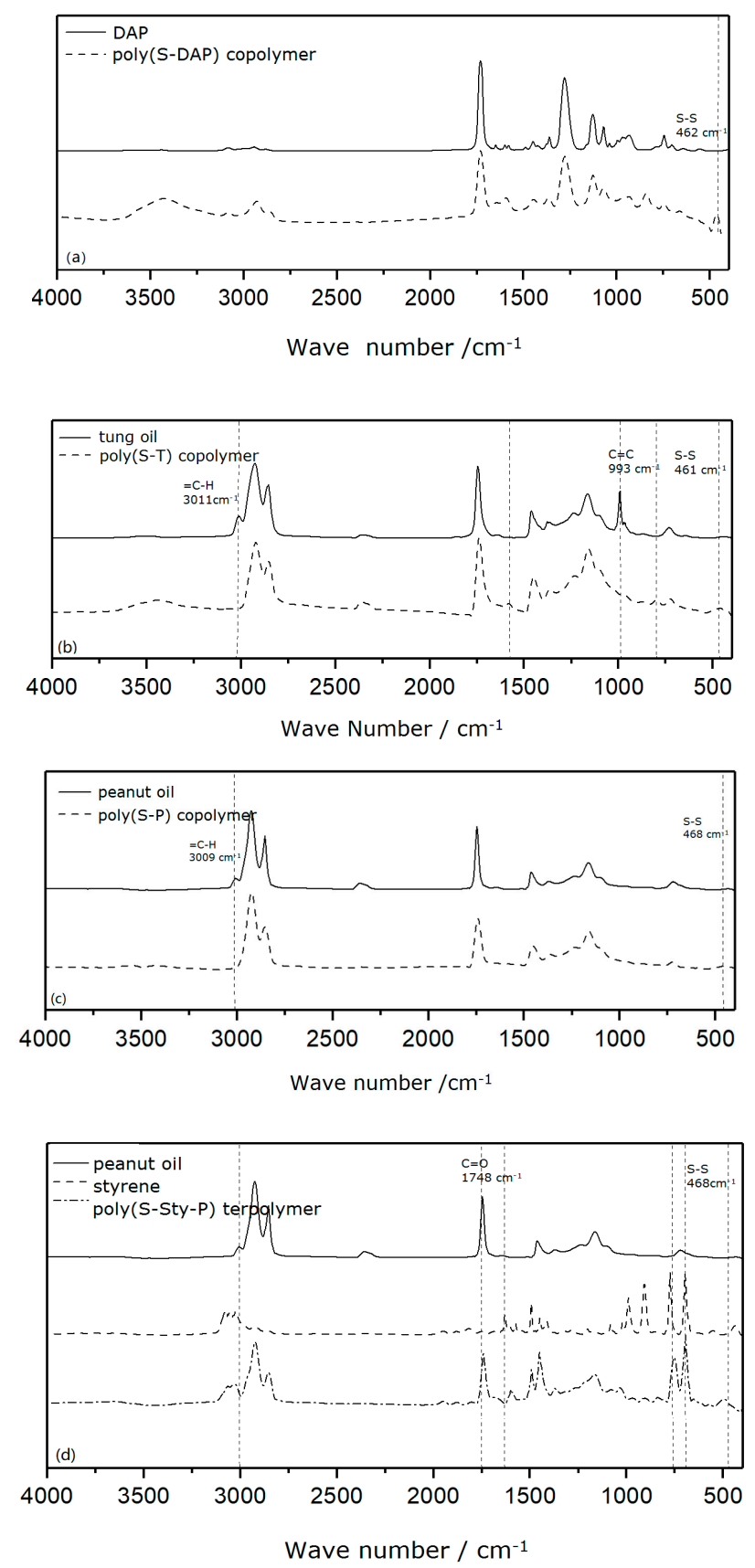

Figure 5. (a) The infrared spectrum of poly(S-DAP) copolymer and contrast DAP; (b) the infrared spectrum of poly(S-T) copolymer and contrast tung oil; (c) the infrared spectrum of poly(S-P) copolymer and contrast peanut oil; (d) the infrared spectrum of poly(S-Sty-P) terpolymer and contrast peanut oil, styrene.

In order to be fully blended with conductive additives and to be uniformly filled on the collector, the products were separately dissolved in different solvents to find out the most suitable system. The poly(S-DAP) copolymer, poly(S-T) copolymer, poly(S-P) copolymer, and poly(S-Sty-P) terpolymer were separately added into different solvents: Acetone, dichloromethane, trichloromethane, cyclohexane, toluene, and tetrahydrofuran. The mixture was separately put into ultrasonic cleaners for $25 \mathrm{~min}$ and stayed still for $24 \mathrm{~h}$. The result showed that poly(S-Sty-P) terpolymer had the best solubility in tetrahydrofuran, as shown in Table 1 . The solubility of this disulfide polymer was based on their molecular chain structure. Tung oil had three conjugated $\mathrm{C}=\mathrm{C}$ bonds in the structure and DAP had two $\mathrm{C}=\mathrm{C}$ bonds, which can easily form a cross-linking structure after reverse vulcanization $[12,20]$. 
Therefore, these two copolymers had worse solubility. Peanut oil contained many unsaturated glycerides. Though it had fewer $\mathrm{C}=\mathrm{C}$ bonds, molecular crosslinking still existed [21]. Therefore, its solubility was still unsatisfactory. However, in the structure of poly(S-Sty-P) terpolymer, the benzene ring existed, so the internal crosslinking of the molecular chain was reduced by the larger steric hindrance [22]. Thus, its solubility was improved.

Table 1. The solubility of serial disulfide polymer in different solvents.

\begin{tabular}{|c|c|c|c|c|c|c|}
\hline & Acetone & Dichloromethane & Trichloromethane & Cyclohexane & Toluene & Tetrahydrofuran \\
\hline S-DAP & $\times$ & $\times$ & $\times$ & $\times$ & $x$ & $x$ \\
\hline S-T & $\times$ & $x$ & $\times$ & $\times$ & $x$ & $\bigcirc$ \\
\hline S-P & $\times$ & $\bigcirc$ & $\bigcirc$ & $\bigcirc$ & $\bigcirc$ & $\bigcirc$ \\
\hline S-Sty-P & $\times$ & $\bigcirc$ & $\bigcirc$ & $\bigcirc$ & 0 & $\sqrt{ }$ \\
\hline
\end{tabular}

Furthermore, nuclear magnetic resonance carbon $\left({ }^{13} \mathrm{C}\right.$ NMR) characterization was used to demonstrate the terpolymer's structure. In the ${ }^{13} \mathrm{C}$ NMR spectra of poly(S-Sty-P) terpolymer (Figure 6), the signals at the range of 125-129 ppm were attributed by the $C=C$ bond vibration. It meant that benzene ring existed in the molecular chain of the terpolymer. However, intramolecular crosslinks might also exist during the reaction, as shown in Figure 6. There were also new signals at 51 and $21 \mathrm{ppm}$, which indicated that carbon atoms were successfully attached to sulfur.

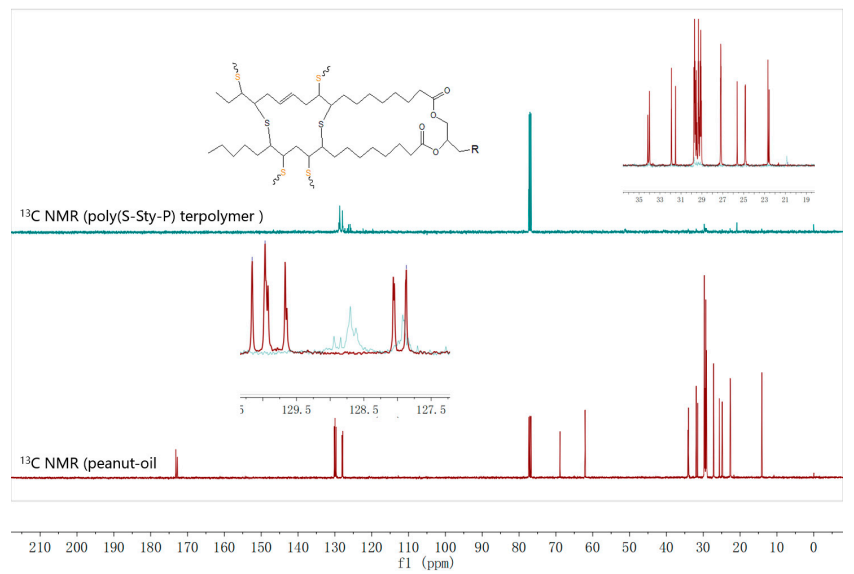

Figure $6 .{ }^{13} \mathrm{C}$ NMR characterization of poly(S-Sty-P) terpolymer and intramolecular crosslinks.

As poly(S-Sty-P) terpolymer had the best solubility compared with other disulfide polymers, it was chosen to be utilized as the cathode material in Li-S battery. Conductive carbon black and graphene were separately blended with it (poly(S-Sty-P) terpolymer blended with conductive carbon black-poly(S-Sty-P) terpolymer @ CCB; poly(S-Sty-P) terpolymer blended with graphenepoly(S-Sty-P) terpolymer @ GF), and SEM was utilized to investigate the morphologies of the compounds. As depicted in Figure 7a, poly(S-Sty-P) terpolymer @ GF showed a lamellar-like structure on the surface. In this structure, the active particles were attached to the graphene sheet, forming a large area of conductive network which provided a large number of conductive contact sites [23,24]. Additionally, Figure 7b showed the structure of poly(S-Sty-P) terpolymer @ CCB. The particles were clustered into a chain or grape structure, packed closely, which was advantageous to form a conductive chain structure in the electrode [25]. Elemental analysis showed that there was a large amount of $S$ element in the two compounds. 

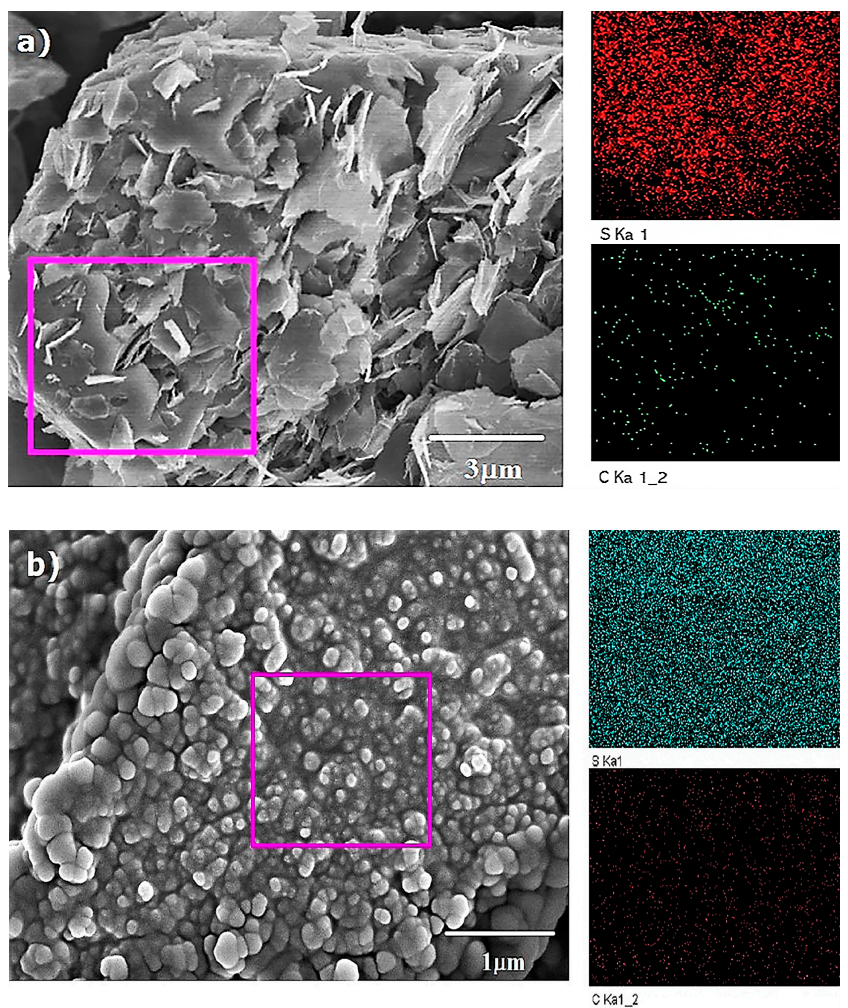

Figure 7. (a) SEM of poly(S-Sty-P) terpolymer @ GF; (b) SEM of poly(S-Sty-P) terpolymer @ CCB.

\subsection{Electrochemical Measurement}

The poly(S-Sty-P) terpolymer @ GF and poly(S-Sty-P) terpolymer @ CCB were both successfully employed as cathode materials in Li-S battery. The first cycle of cyclic voltammetry (CV) curves of these two batteries were depicted in Figure 8. The CV curve of poly(S-Sty-P) terpolymer @ CCB resembled the curve of charge-discharge curves of poly(S-Sty-P) terpolymer @ GF. They both had two distinct reduction peaks at about 2.3 and $2.1 \mathrm{~V}$, and one oxidation peak at $2.4 \mathrm{~V}$. Both of the curves were characteristic of the CV curve of element sulfur [26].

With the open circuit voltage of $3 \mathrm{~V}$ and current of $0.2 \mathrm{C}$, the charge-discharge curve of poly(S-Sty-P) @ CCB battery showed two plateaus (Figure $9 \mathrm{a}$ ) at 2.35 and $2.05 \mathrm{~V}$; and the charge-discharge curve of poly(S-Sty-P) @ GF battery showed two plateaus (Figure 9b) at 2.33 and $2.03 \mathrm{~V}$. Both of the charge-discharge curves were in accordance with the characteristic curve of Li-S battery. This fact demonstrated that S-S and organosulfur moieties in the terpolymers were electroactive. The reactions involved during the charge and discharge process were shown in Figure 10.
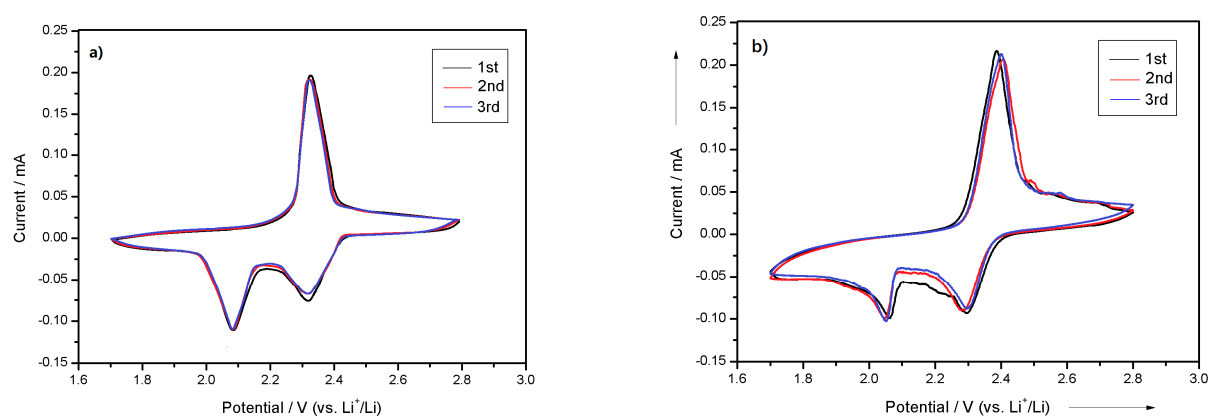

Figure 8. (a) The first cycle of cyclic voltammetry (CV) curves of poly(S-Sty-P) terpolymer @ CCB battery; (b) the first cycle of CV curves of poly(S-Sty-P) terpolymer @ GF battery. 

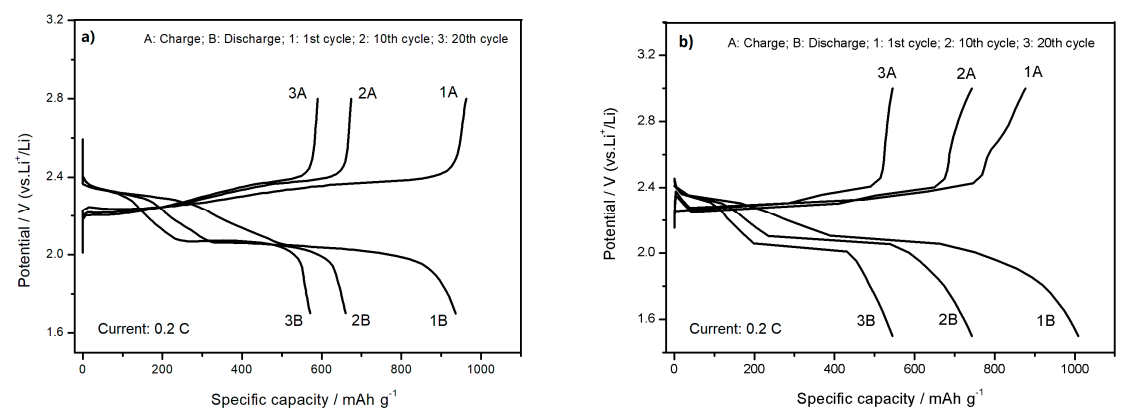

Figure 9. (a) The charge-discharge curves of poly(S-Sty-P) terpolymer @ CCB battery; (b) the charge-discharge curves of poly(S-Sty-P) terpolymer @ GF battery.

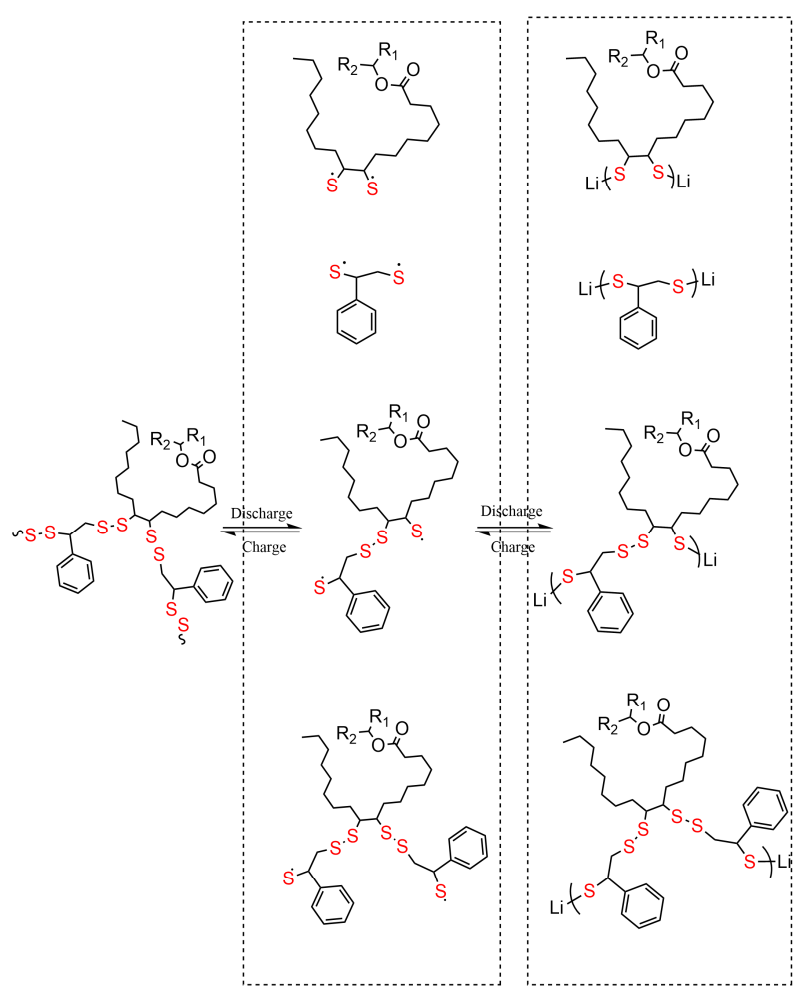

R1, R2: palmitate, stearate, linolenate, arachidate, behenate, oleate, leicosenoicate, etc

Figure 10. The reactions involved during the charge and discharge process.

From Figure 11, it can be seen that the initial specific capacity of poly(S-Sty-P) terpolymer @ CCB battery was $935.88 \mathrm{mAh} / \mathrm{g}$. After 60 cycles, the specific capacity gradually decreased to $542.71 \mathrm{mAh} / \mathrm{g}$. After 100 cycles, the specific capacity stayed at $407 \mathrm{mAh} / \mathrm{g}$, with the coulombic efficiency around $100 \%$ and the capacity retention rate about $43.5 \%$. Comparatively, the initial specific capacity of poly(S-Sty-P) terpolymer @ GF battery was $1008.35 \mathrm{mAh} / \mathrm{g}$, and the discharge specific capacity reduced to $639.03 \mathrm{mAh} / \mathrm{g}$ after 60 cycles, and maintained at $611 \mathrm{mAh} / \mathrm{g}$ after 100 cycles, with the capacity retention rate around $60.59 \%$. Therefore, it had a better cycle stability. This was because the functional groups of poly(S-Sty-P) terpolymer can capture the intermediate polysulfides, and subsequently suppress polysulfide diffusion as a consequence of the embedment [5]. In addition, the S-S bonds in the terpolymer were involved with the $\pi-\pi$ conjugation of graphene [27], expanding the conjugated system, which effectively enhanced the interaction on the positive electrode interface and limited the "shuttle effect" of polysulfides [28]. Therefore, the electrochemical performance of the Li-S battery was improved. 


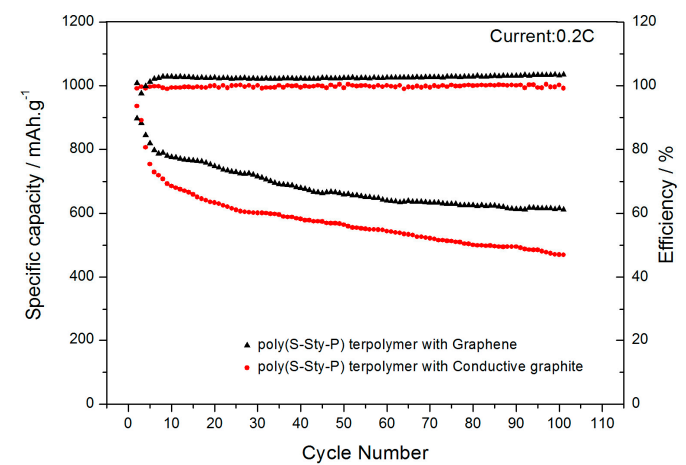

Figure 11. The cycle performance of poly(S-Sty-P) terpolymer @ CCB battery and poly(S-Sty-P) terpolymer@ GF battery.

When the current densities were gradually increased from $0.2,0.5,1,2$, to $5 \mathrm{C}$, with 10 cycles at each current density, the rate performance of the batteries were obtained (Figure 12). At different current densities, the discharge specific capacities of poly(S-Sty-P) terpolymer @ CCB battery were 935.4, 580.04, $434.92,286.32$, and $277.68 \mathrm{mAh} / \mathrm{g}$. When the current density was back to $0.2 \mathrm{C}$, the discharge specific capacity of this battery was about $431.12 \mathrm{mAh} / \mathrm{g}$. Comparatively, the discharge specific capacities of poly(S-Sty-P) terpolymer @ GF battery were 1008, 688.68, 531.18, 435.42, and $302.90 \mathrm{mAh} / \mathrm{g}$. When the current density was back to $0.2 \mathrm{C}$, the discharge specific capacity of this battery was about $515.52 \mathrm{mAh} / \mathrm{g}$, suggesting better rate performance. Since, compared with the conductive carbon black particle's structure, the graphene sheet had a larger specific surface area, higher stratified porosity, and more contact sites which can touch more active substances $[29,30]$. This structure was conducive to the infiltration of the electrolyte, resulting in the shorter diffusion path for lithium-ion. Under high current density, lithium-ion can easily transfer [31], so this battery had better rate performance.

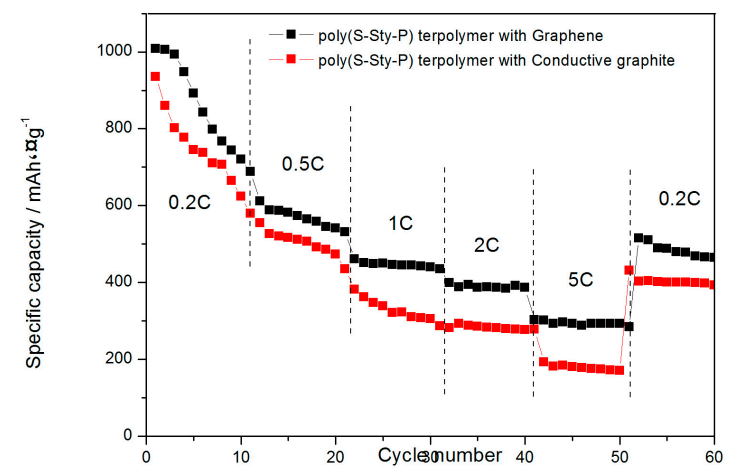

Figure 12. The rate performance of poly(S-Sty-P) terpolymer @ CCB battery and poly(S-Sty-P) terpolymer@ GF battery.

The electrochemical impedance spectroscopy (EIS) of the cathode material was also measured. From Figure 13, it can be seen that the poly (S-Sty-P) @ GF cathode material exhibited a relatively lower charge transfer impedance than the poly (S-Sty-P) @ CCB cathode material. Since graphene had a flake structure, the active material particles can be attached onto the sheet layers of graphene, which provided more conductive contact sites [24] and formed a large-area conductive network. 


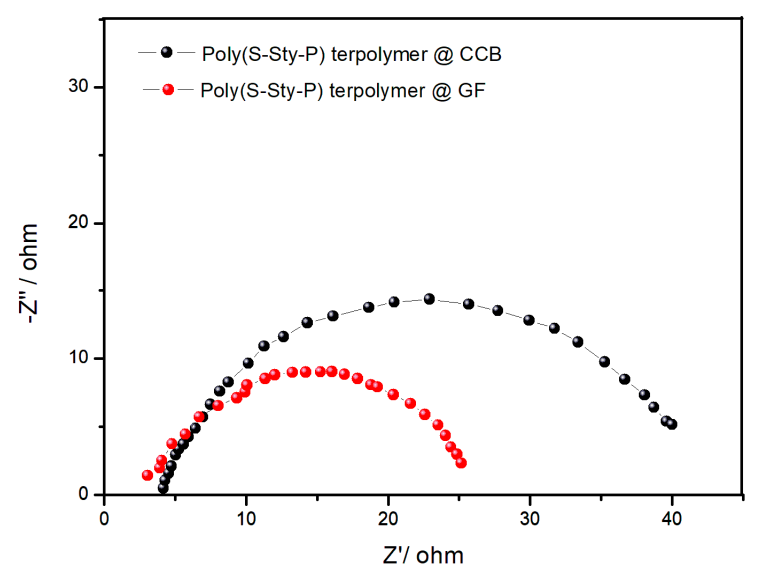

Figure 13. The electrochemical impedance spectroscopy (EIS) of poly(S-Sty-P) terpolymer @ CCB cathode material and poly(S-Sty-P) terpolymer @ GF cathode material.

\section{Conclusions}

In this paper, a series of disulfide polymers were synthesized from lower-cost raw materials, such as diallyl-o-phthalate, tung oil, peanut oil, and styrene. Four products: Poly (sulfur-diallyl-o-phthalate) copolymer, poly (sulfur-tung oil) copolymer, poly (sulfur-peanut oil) copolymer, and poly (sulfur-styrene-peanut oil) terpolymer were prepared and characterized. After the solubility test, the result showed that disulfide poly(S-Sty-P) terpolymer had the best solubility and can be both utilized as an active cathode material and binder in Li-S battery.

The initial specific capacity of poly(S-Sty-P) terpolymer @ CCB battery was $935.88 \mathrm{mAh} / \mathrm{g}$, with the capacity retention rate about $43.5 \%$. Comparingly, the initial specific capacity of poly(S-Sty-P) terpolymer @ GF battery was $1008.35 \mathrm{mAh} / \mathrm{g}$, with the capacity retention rate around $60.59 \%$. Therefore, the poly(S-Sty-P) terpolymer @ GF battery showed a more stable cycle performance and better capacity retention abilities. In the rate test, the poly(S-Sty-P) terpolymer @ GF battery also showed a better rate performance, comparingly. It suggested that the S-S bonds of poly(S-Sty-P) terpolymer @ GF can enhance the interaction of the positive electrode interface, effectively control the "shuttle effect" of polysulfides, and greatly improve battery performances. This result not only showed the importance of material optimization and construction for the Li-S battery, but also provided the idea of preparing cathode materials by using environmental-friendly materials, which had a great value for modern battery research.

Author Contributions: J.W. designed experiments, carried out the experiments, analyzed experimental results, sequenced data and wrote the manuscript. S.Z. provided a guide for the experiment, refined the ideas, carried out additional analyses and finalized this paper. All authors have read and agreed to the published version of the manuscript.

Funding: National Natural Science Foundation of China (51774017).

Acknowledgments: We gratefully acknowledge the assistance of Zhixu Jian and Heliang Zhou for helping with the battery test.

Conflicts of Interest: The authors declare no conflict of interest

\section{References}

1. Manthiram, A.; Fu, Y.; Su Y, S. Challenges and prospects of lithium/sulfur batteries. Acc. Chem. Res. 2012, 46, 1125-1134. [CrossRef] [PubMed]

2. Ji, X.L.; Lee, K.T.; Nazar, L.F. A highly ordered nanostructured carbon-sulphur. Nat. Mater. 2009, 8, 500-506. [CrossRef] [PubMed]

3. Meng, Y.; Han, D.; Xiao, M. A Preparation Method of Sulfur Polymer as Cathode Material of Lithium Sulfur Battery. China Patent CN102664264A, 12 September 2012. 
4. Rowan, S.J.; Cantrill, S.J.; Cousins, G.R.; Sanders, J.K.; Stoddart, J.F. Dynamic covalent chemistry. Angew. Chem. Int. Ed. 2002, 41, 898-952. [CrossRef]

5. Jian, Z.; Li, H.; Cao, R.; Zhou, H.; Xu, H.; Zhao, G.; Xing, Y.; Zhang, S. Polydopamine-coated hierarchical tower-shaped carbon for high-performance lithium-sulfur batteries. Electrochim. Acta 2019, 319, 359-365. [CrossRef]

6. Mustafa, A.; Baris, K.; Yusuf, Y. Combining Elemental Sulfur with Polybenzoxazines via Inverse Vulcanization. RSC Adv. 2019, 9, 31460-31465.

7. Deng, Z.; Hoefling, A.; Théato, P.; Lienkamp, K. Surface properties and antimicrobial activity of poly(sulfur-co-1,3-diisopropenylbenzene) copolymers. Macromol. Chem. Phys. 2018, 219, 1700497. [CrossRef]

8. Chung, W.J.; Griebel, J.J.; Kim, E.T.; Yoon, H.; Simmonds, A.G.; Ji, H.J.; Dirlam, P.T.; Glass, R.S.; Wie, J.J.; Nguyen, N.A.; et al. The use of elemental sulfur as an alternative feedstock for polymeric materials. Nat. Chem. 2013, 5, 518-524. [CrossRef]

9. Griebel, J.J.; Li, G.; Glass, R.S.; Char, K.; Pyun, J. Kilogram scale inverse vulcanization of elemental sulfur to prepare high capacity polymer electrodes for Li-S batteries. J. Polym. Sci. Part A Polym. Chem. 2014, 53, 173-177. [CrossRef]

10. Shahrukh, Z.; Khawaja, S.; Vijay, K.; Kishore, K.; Jena, S.M. Alhassan. Flexible sulfur film from inverse vulcanization technique. Mater. Lett. 2017, 203, 58-61.

11. Dirlam, P.T.; Glass, R.S.; Char, K.; Pyun, J. The use of polymers in Li-S batteries: A review. J. Polym. Sci. Part A Polym. Chem. 2017, 55, 1635-1668. [CrossRef]

12. Philip, T.D.; Adam, G.S.; Shallcross, R.C.; Kyle, J.A. Improving the Charge Conductance of Elemental Sulfur via Tandem Inverse Vulcanization and Electropolymerization. ACS Macro Lett. 2015, 4, 111-114.

13. Zhenjie, S.; Min, X.; Shuanjin, W.; Dongmei, H. Sulfur-rich polymeric materials with semi- interpenetrating network structure as a novel lithium-sulfur cathode. J. Mater. Chem. A 2014, 2, 9280-9286.

14. Arslan, M.; Kiskan, B.; Cengiz, E.C.; Demir-cakan, R.; Yagci, Y. Inverse vulcanization of bismaleimide and divinylbenzene by elemental sulfur for lithium sulfur batteries. Eur. Polym. J. 2016, 80, 70-77. [CrossRef]

15. Inaki, G.; David, M.; Alberto, B.J.; Olatz, L.; Hicham, B.Y.; Chunmei, L.; Juan, L.G.; Oleksandr, B.; Lide, R.M. Inverse vulcanization of sulfur with divinylbenzene: Stable and easy processable cathode material for lithium-sulfur batteries. J. Power Sources 2016, 329, 72-78.

16. Swapnil, S.; Arnab, G.; Prasun, K.R.; Sagar, M.; Bimlesh, L. Cardanol benzoxazines e A sustainable linker for elemental sulphur based copolymers via inverse vulcanization. Polymer 2016, 99, 349-357.

17. Zhang, Y.Y.; Konopka, K.M.; Glass, R.S.; Char, K.; Pyun, J. Chalcogenide hybrid inorganic/organic polymers (CHIPs) via inverse vulcanization and dynamic covalent polymerizations. Polym. Chem. 2017, 8, 5167-5173. [CrossRef]

18. Liu, J.; Ueda, M. High refractive index polymers: Fundamental research and practical applications. J. Mater. Chem. 2009, 19, 8907-8919. [CrossRef]

19. Calatldo, F. A study on the structure and properties of polymeric sulfur. Angew. Makromol. Chem. 1997, 249, 137-149. [CrossRef]

20. Adam, G.S.; Jared, J.G.; Jungjin, P.; Kwi, R.K. Inverse vulcanization of element sulfur to prepare polymer electrode materials for Li-S batteries. ACS Macro Lett. 2014, 3, 229-232.

21. Zeng, S.; Li, L.; Zhao, D.; Liu, J. Polymer-Capped Sulfur Copolymers as Lithium-Sulfur Battery Cathode: Enhanced Performance by Combined Contributions of Physical and Chemical Confinements. J. Phys. Chem. C 2017, 12, 2495-2503. [CrossRef]

22. Deng, S.R.; Kong, L.B.; Hu, G.Q.; Wu, T.; Li, D.; Zhou, Y.H.; Li, Z.Y. Benzene-based polyorganodisulfide cathode materials for secondary lithium batteries. Electrochim. Acta 2006, 13, 2589-2593. [CrossRef]

23. Wang, S.; Zhou, Q.; Zhou, C.; Wu, J. Research status quo of sulfur electrode for lithium/ sulfur battery. Battery Bimon. 2010, 40, 232-235.

24. Zeng, S.; Li, L.; Xie, L.; Zhao, D.; Zhou, N.; Wang, N.; Chen, S.W. Graphene-supported highly crosslinked organosulfur nanoparticles as cathode materials for high-rate, long-life lithium-sulfur battery. Carbon 2017, 122, 106-113. [CrossRef]

25. Robert, D.; Miran, G.; Jernej, D.; Marjan, B.; Stane, P.; Janko, J. The role of carbon black distribution in cathodes for Li ion batteries. J. Power Sources 2003, 119, 770-773.

26. Wojtecki, R.; Meador, M.; Rowan, S. Using the dynamic bond to access macroscopically responsive structurally dynamic polymers. Nat. Mater 2011, 10, 14-27. [CrossRef] 
27. Park, S.; An, J.; Potts, J.R.; Aruna, V. Hydrazine-reduction of graphite-and grapheneoxide. Carbon 2011, 49, 3019-3023. [CrossRef]

28. Hou, T.Z.; Xu, W.T.; Chen, X.; Peng, H.J.; Huang, J.Q.; Zhang, Q. Lithium Bond Chemistry in Lithium-Sulfur Batteries. Angew. Chem. Int. Ed. 2017, 56, 8178-8182. [CrossRef]

29. Xavier, B. Electrically Conductive Grades of Carbon Black: Structure and Properties. Carbon 1993, 31, $287-302$.

30. Dan, L.; Marc, B.M.; Scott, G.; Richard, K. Processable aqueous dispersion of graphene nanosheets. Nat. Nanotechnol. 2008, 3, 101-105.

31. Arnab, G.; Swapnil, S.; Gaganpreet, S.K.; Bimlesh, L. Sustainable Sulfur-rich Copolymer/Graphene Composite as Lithium-Sulfur Battery Cathode with Excellent Electrochemical Performance. Sci. Rep. 2016, 6, 25207.

(C) 2020 by the authors. Licensee MDPI, Basel, Switzerland. This article is an open access article distributed under the terms and conditions of the Creative Commons Attribution (CC BY) license (http://creativecommons.org/licenses/by/4.0/). 